\title{
DISCARDED NYLON FISHING NETS AS FIBRE REINFORCEMENT IN CEMENT MORTAR
}

\author{
LISBETH M. OTTOSEN, SIMON J. SVENSSON \& IDA M. G. BERTELSEN \\ Department of Civil Engineering, Technical University of Denmark, Denmark
}

\begin{abstract}
This work builds on an idea of utilizing fibres cut from waste fishing nets for fibre reinforcement of concrete. An experimental investigation of waste fishing net polyfilament fibres of nylon 6 is reported. Differential Scanning Calorimetry confirmed the net to be nylon 6. SEM images showed that the polyfilaments consisted of twisted monofilaments (diameter 24-31 $\mu \mathrm{m}$ ). The diameter of the polyfilaments was about $1.2 \mathrm{~mm}$. The investigation consists of two major parts; properties of the polyfilaments and properties of mortar specimens reinforced with the polyfilaments. The tensile strength of the polyfilaments was about $260 \mathrm{MPa}$, which is low compared to the 540-1080 MPa for new nylon 6 even considering that the tensile strength was measured for polyfilaments. An even larger decrease was seen for Youngs Modulus, which was found to only about $330 \mathrm{MPa}$ compared to 1-3 GPa for new nylon 6. On exposure to UV radiation over a long period, nylon 6 undergo photo-oxidative degradation and this is suggested to be the major cause for the loss of tensile strength and elasticity. The few other studies reporting properties of waste nylon 6 fishing nets also reports losses. Mortar specimens were reinforced with 0.5 to $2.0 \mathrm{wt} . \%$ waste fishing net fibres. Both flexural strength and compressive strength decreased slightly compared to the reference, but the fibre-reinforced mortar specimens all showed considerable post-peak resources and the toughness index (I5) was about 5. For comparison, mortar prisms were reinforced with commercial fibres, and for these the I5 was about 7 , i.e. higher, but the results obtained with the waste fishing net polyfilaments were still highly encouraging in relation to use as fibre reinforcement of concrete.
\end{abstract}

Keywords: fibre reinforced concrete, waste fishing net, nylon 6, polyfilament fibres.

\section{INTRODUCTION}

The presence of plastic in the marine environment is a globally recognised environmental issue, with far reaching economic, aesthetic, and environmental consequences [1]. Marine plastic litter is of growing concern, and one particular troublesome marine waste fraction is discarded fishing gear. Increasing levels of marine litter is particularly pertinent to the Arctic region, and the EU financed Circular Ocean project, under which the present work is conducted, focuses on adding value to waste fishing nets by identifying options for use as secondary resources. It is important to the environment that waste fishing nets are not discarded at sea. However, when the waste fishing nets are brought to land, they are piling up in the landfills. In Greenland for example, it appears that all types of polymer waste fishing nets and ropes (nylon, PE and PP) go to landfill due to a lack of reuse and recycling infrastructure [2]. At the same time, Greenland is characterized by scarcity in local resources for production of construction materials, and following construction materials are transported to the country over long distances. One use for the waste fishing nets could be for fibre reinforcement of concrete. Use of waste fishing nets from polyethylene was investigated in [3] and this project investigates technically whether fibres from waste fishing nets of nylon 6 can be utilized for this purpose. If successful, these waste fishing nets can be regarded as a local resource. The recycling of waste fishing nets for reinforcement does not require any energy consuming processes such as material re-polymerization or extrusion. The nets simply need to washed and properly cut to obtain reinforcing fibers, resulting in a substantial reduction in costs and energy consumption [4]. 
Previous studies have suggested to process waste fishing nets into fibres to reinforce concrete [3]-[5]. Studies [4], [5] deals with nylon fibres as the present, however, in both studies, the nylon were used as monofilaments, whereas in the present study the nylon fibres were used as polyfilaments. Spadea et al. [4] investigated the static mechanical properties of fibre-reinforced mortar by using recycled nylon monofilament fibre from abandoned fishing nets. They found significantly improved toughness and ductility. Orasutthikul et al. [5] found that recycled nylon monofilament fibre for reinforcement of mortars were as beneficial in terms of flexural strength, material toughness and residual strength as reinforcement with virgin fibres, even if a higher fibre fraction was required to match the performance.

\section{MATERIALS AND METHODS}

The waste fishing net in this work was an outer net of Nylon 6 with a rather large mesh size of $33 \times 33 \mathrm{~cm}$ (Fig. 1(b)) collected in Gilleleje, Denmark in 2016. The net was processed into fibres (Section 2.1) and the experimental work had two parts: properties of the fibres (Section 2.2) and properties of cement mortar with fibres (Section 2.3).

\subsection{Preparation of fishing net fibres}

Impurities and salts were washed off the fishing net by soaking in tap water for 30 minutes. The soaking procedure was repeated four times in new tap water. The conductivity in the water after soaking was at the same level as the tap water itself after the fourth soaking. This was used as indication of sufficient washing.

The net was cut by hand into 2 and $4 \mathrm{~cm}$ long strings for the experimental work (Fig. 2(b)). The tolerance length of the fibres was $\pm 5 \%$ of the length, in accordance to [6]. The strings were made of three twisted bundles (polyfilaments) of single fibres (monofilaments).

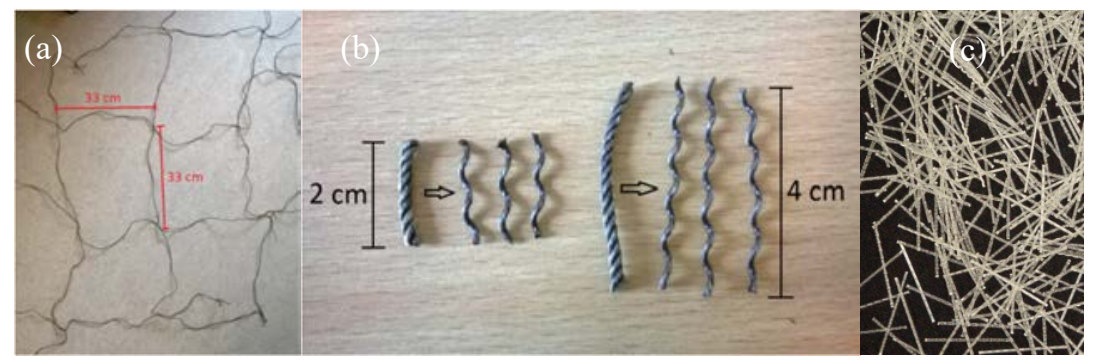

Figure 1: (a) The net with mesh size; (b) Cut fishing net fibre strings at two lengths and three untwisted polyfilaments from each; and (c) DURUS macro fibres.

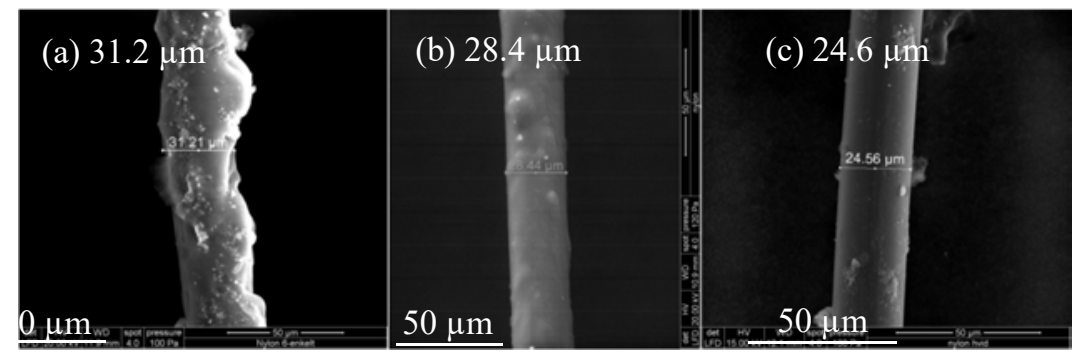

Figure 2: SEM images of (a) thick, (b) medium and (c) thin monofilaments. 
Before the tests, the strings were untwisted, and the experimental work was made with such polyfilaments (Fig. 1(b)). Polyfilaments instead of monofilaments were chosen to increase the surface area and take advantage of the non-straight shape of the polyfilaments, which are expected to have better attachment in the mortar and less risk of pull-out, as found by [7].

\subsection{Fishnet fibre properties}

The diameter of mono- and polyfilaments were estimated from SEM images. To confirm the polymer type of the fishnet Fourier Transform Infrared Spectroscopy (FTIR) was used (PerkinElmer Spectrum One model 2000). The thermal degradation as a function of temperature was investigated by Thermal Gravimetric Analysis (TGA) and Differential Scanning Calorimetry (DSC). The test was performed on a TA Q500 with a sample of $10 \mathrm{mg}$ fibre, where the temperatures ranged from room temperature at $20^{\circ} \mathrm{C}$ to $800^{\circ} \mathrm{C}$ with an increase in temperature of $10^{\circ} \mathrm{C} / \mathrm{min}$. The alkali resistance of the fibres were investigated by submerging fibre samples in $1 \mathrm{M} \mathrm{NaOH}$ for 28 days in an oven at $40^{\circ} \mathrm{C}$ after the procedure from [8]. After immersion, both mono- and polyfilaments were examined in SEM.

Uniaxial tensile strength and Youngs modulus were determined for the polyfilaments in accordance with [6]. Polyfilament strings (150 mm long) were mounted at the centre of thick paper with a hollow section of $20 \mathrm{~mm}, 25 \mathrm{~mm}$ or $30 \mathrm{~mm}$. As prescribed in [6], these three different gage lengths were tested in order to determine Youngs modulus. The fibre was anchored on the paper with WEICON PP-PE 2-component glue. Tensile load was applied in a displacement controlled Instron 6022 machine with constant displacement rate of $20 \mathrm{~mm} / \mathrm{min}$. A successful failure was on the free length of the fibre. Eight tests were carried out for each gauge length. The properties were measured before and after alkali resistance tests.

\subsection{Properties of cement-based mortar with fishnet fibres}

The basic mortar recipe was in accordance with [9] and the materials were prepared according to [10]. The basic recipe in the standards was for mortar without fibres. The fibres were added after mixing water/cement/sand and the prescribed rest period i.e. just before the prescribed last mixing at fast speed. The standard sand prescribed in [9] was replaced with sea sand $(0-$ $4 \mathrm{~mm}$ ). The basic recipe was $450 \pm 2 \mathrm{~g}$ cement (CEM II/A-LL), $225 \pm 1 \mathrm{~g}$ tap water and 1350 $\pm 5 \mathrm{~g}$ sea sand. The polyfilaments were added to the mortar mixture at weight percentage of $0.5 \%, 1.0 \%$ and $2.0 \%$ (corresponding to $10.13 \mathrm{~g}, 20.25 \mathrm{~g}$ and $40.50 \mathrm{~g}$ ). For comparison, similar castings with Durus S400 from Bonar N.V. commercial fibres were made. For each mixture, three mortar specimens were cast $(40$ x 40x $160 \mathrm{~mm})$. Table 1 shows the fibre content and curing of the specimens.

Three-point bending tests were carried out in accordance with [9]. A hydraulic Instron 6022 recorded the working curves. The load was applied at the middle of the mortar prism

Table 1: Fibre content and curing of mortar prisms.

\begin{tabular}{|l|c|c|}
\hline Fibre & Fibre content (wt.\%) & Curing(days) \\
\hline Fishnet $2 \mathrm{~cm}$ & $0.5,1.0,2.0$ & $7,14,28$ \\
\hline Fishnet $4 \mathrm{~cm}$ & $0.5,1.0,2.0$ & 28 \\
\hline Durus S400 & $1.0,2.0$ & 28 \\
\hline No fibres (reference) & 0 & $7,14,28$ \\
\hline
\end{tabular}


until fracture for the reference samples, or post-break strength starting to decrease significantly for the fibre reinforced samples. The supports were placed $100 \mathrm{~mm}$ apart. The load was applied by the rate $2 \mathrm{~mm} / \mathrm{min}$. The compressive strength was measured in after the three point bending test as described in [9]. The load was applied on a $40 \times 40 \mathrm{~mm}$ surface in each end of the specimen until rupture (making a double determination for each specimen).

\section{RESULTS}

\subsection{Characteristics of fishnet fibres}

Figs 2 and 3(a) are SEM images of monofilaments and polyfilaments, respectively. Analysis of several SEM images showed that the diameter of the monofilaments was between $25 \mu \mathrm{m}$ to $31 \mu \mathrm{m}$, with the most appearing diameter being $28 \mu \mathrm{m}$. There was a clear tendency for the more rough the surface of the single fibre, the larger the diameter. The diameter of a polyfilament was approximately $1.2 \mathrm{~mm}$.

Fig. 3(b) shows the FTIR spectrum. Using OMNIC Specta showed Nylon 6 with 83.2\% certainty. There was some noise on the spectrum at low wavelengths due to impurities resulting in the relatively low certainty in determining the material type. Fig. 4(a) shows the results from DSC. The final warm-up (yellow) is the heating flow for the true polymer without impurities. The melting point corresponds to the lowest point i.e. $214^{\circ} \mathrm{C}$. The difference in first and second warm-up in the DSC spectrums supports the presence of
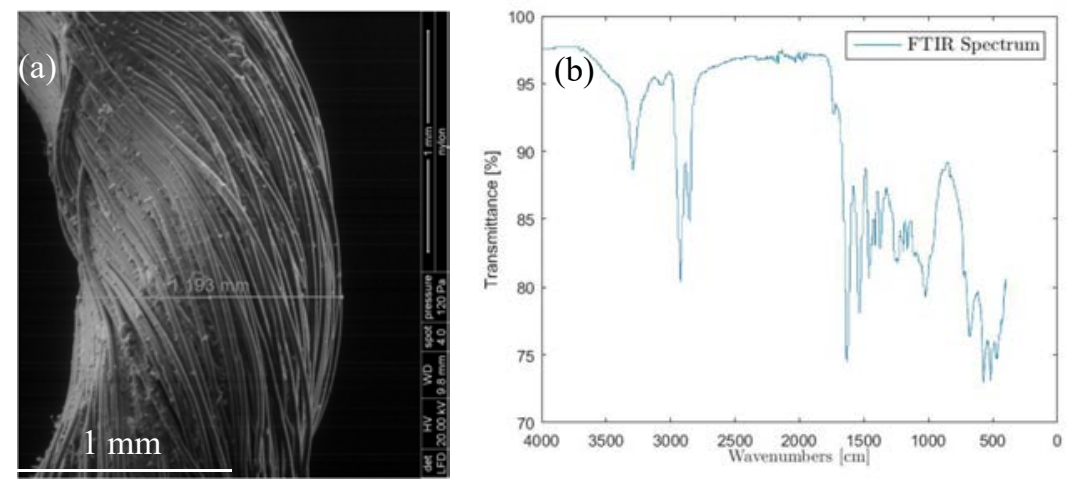

Figure 3: (a) SEM images of waste fishing net polyfilament; and (b) FTIR spectrum.
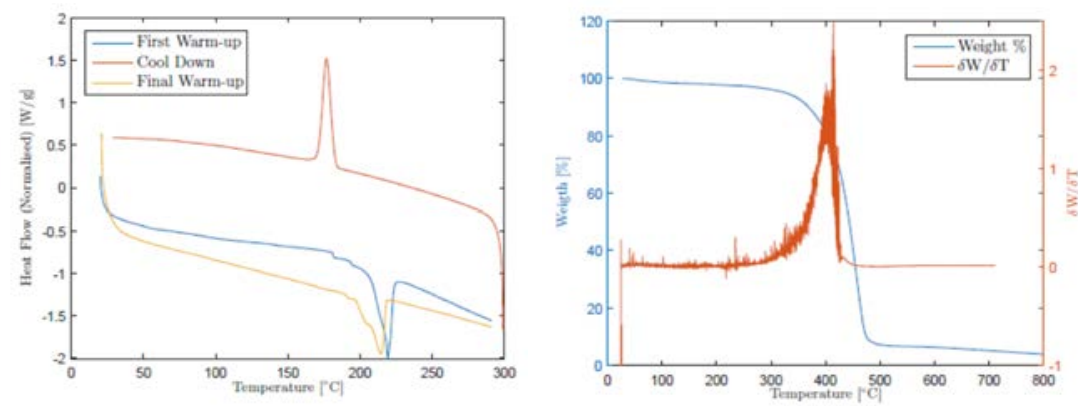

Figure 4: (a) Differential scanning calorimetry; and (b) Thermal gravimetric analysis. 
impurities. The melting point of nylon 6 is $215^{\circ} \mathrm{C}$ and for nylon 6.6 it is $260^{\circ} \mathrm{C}$ [11], and thus the fishing net polymer itself is confirmed as Nylon 6 , as the melting point was $214^{\circ} \mathrm{C}$.

Fig. 4(b) is the TGA curve. The loss of material accelerate above $350^{\circ} \mathrm{C}$, which is thus the ignition temperature. The small material loss at lower temperatures again imply impurities. The presence of impurities was thus seen from FTIR, DSC and TGA, and is likely the small particles, which can be seen attached to the polyfilaments (Fig. 3(a)).

Nylon 6 can provide good resistance to most chemicals, but can be attacked by strong acids, alcohols and alkalis [12]. As concrete is highly alkaline, it is important that the fishing net fibres can withstand such high $\mathrm{pH}$. SEM images of the mono- and polyfilaments after submersion in $1.0 \mathrm{M} \mathrm{NaOH}$ are in Fig. 5. The monofilaments visually seemed to be of the same quality before submersion (Fig. 2). The polyfilaments (Fig. 5(b)) were more loose after submersion than before (Fig. 3(b)), but this is not considered to be due to the alkaline solution rather that the fibres are not hold physically together during submersion, resulting in some untwisting. Spadea et al. [4] found that their nylon 6 monofilament fibres presented adequate alkali resistance according to currently recognized standards.

\subsection{Mechanical properties of fishnet fibres}

The tensile strength was found in accordance to [6], but with the important modification that polyfilaments were tested not monofilament. The stress-strain relationship was measured for polyfilaments at each gage length (Fig. 6(a)-(c)). The polyfilaments broke in two different patterns. One where all the monofilaments broke simultaneously and one where they broke in steps. The first is seen by a steep drop in load directly to zero and the second is seen from the steep drop not reaching zero at once, but instead a second strength is shown taking load again before it breaks (e.g. test 7 in Fig. 6(c)).

The tensile strength $\left(\sigma_{t}\right)$, of the polyfilament fibres is calculated as the peak force $\left(\mathrm{F}_{\max }\right)$ divided by the cross-sectional area of the polyfilament. The diameter of cross section of the polyfilament used $1.2 \mathrm{~mm}$, which was the diameter of a tightly twisted bundle (Fig. 4(a)). The results for the different gauge lengths are in Table 2.

Assuming a linear elastic constitutive law and uniaxial load conditions, the following analytical expression applies [4]:

$$
\frac{\Delta L}{F}=\frac{\Delta l}{F}+C_{s}=\frac{l_{0}}{E \cdot A}+C_{s} .
$$

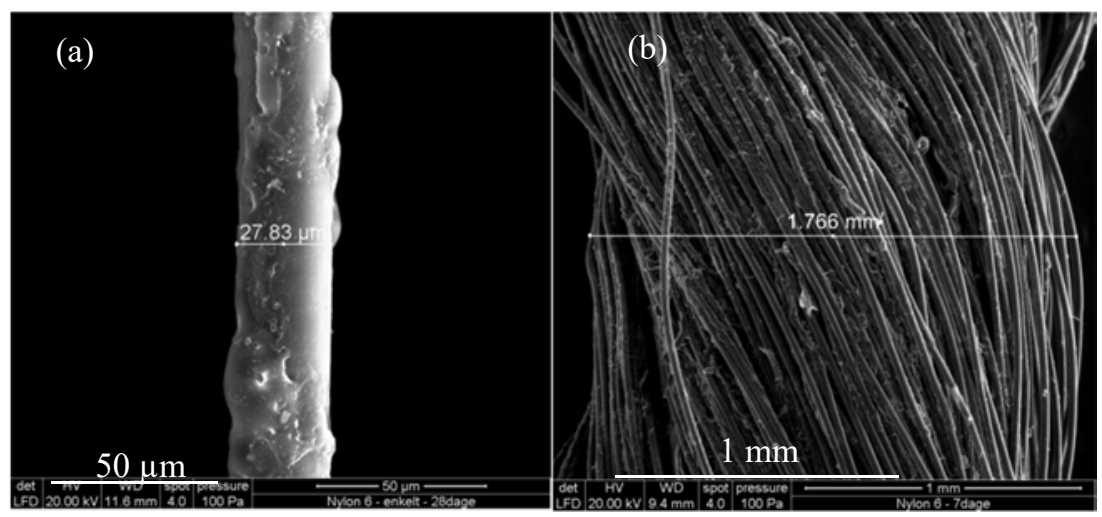

Figure 5: SEM images after submersion in $\mathrm{NaOH}$. (a) Monofilament; and (b) Polyfilament. 


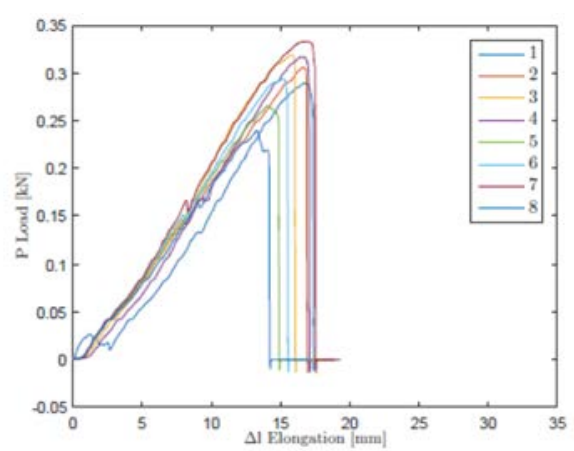

(a)

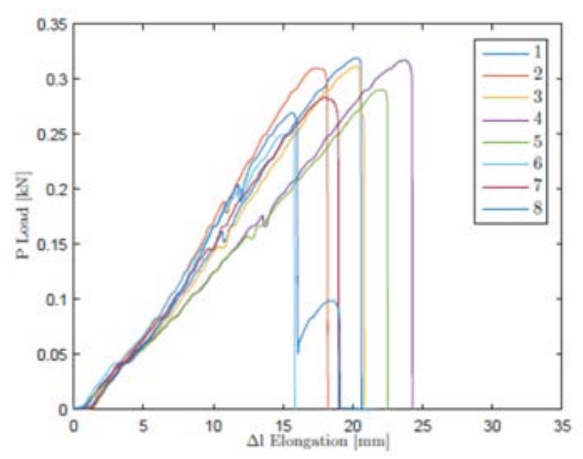

(b)

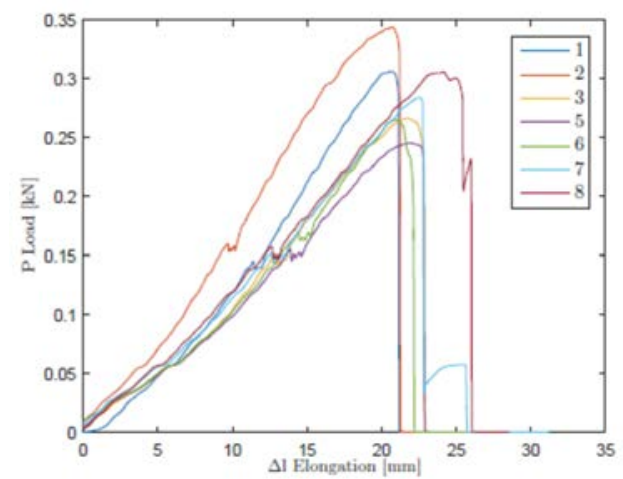

(c)

Figure 6: Stress-strain plots of polyfilaments at different gauge lengths. (a) L20 mm; (b) $\mathrm{L} 25 \mathrm{~mm}$; and (c) L30 $\mathrm{mm}$.

Table 2: Peak strain ( $(\mathrm{t})$ and tensile strength $(\sigma \mathrm{t})$ for the polyfilament fibres.

\begin{tabular}{|c|c|c|c|c|c|}
\hline & $\begin{array}{c}\text { Length } \\
1_{0}(\mathrm{~mm})\end{array}$ & $\begin{array}{c}\text { Peak elongation } \\
\Delta \mathrm{L}(\mathrm{mm})\end{array}$ & $\begin{array}{c}\text { Peak strain } \\
\varepsilon_{\mathrm{t}}(\%)\end{array}$ & $\begin{array}{c}\text { Peak force } \\
\mathrm{F}_{\max }(\mathrm{kN})\end{array}$ & $\begin{array}{c}\text { Tensile } \\
\text { strength } \\
\sigma_{\mathrm{t}}(\mathrm{MPa})\end{array}$ \\
\hline \multirow{4}{*}{ Waste fibre } & 20 & $15.6 \pm 1.3$ & $78 \pm 7$ & $0.30 \pm 0.03$ & $261 \pm 27$ \\
\cline { 2 - 6 } & 25 & $19.5 \pm 2.6$ & $78 \pm 10$ & $0.29 \pm 0.02$ & $261 \pm 29$ \\
\cline { 2 - 6 } & 30 & $22.6 \pm 1.5$ & $75 \pm 4$ & $0.29 \pm 0.02$ & $257 \pm 29$ \\
\cline { 2 - 6 } & Average & - & $77 \pm 7$ & $0.29 \pm 0.02$ & $260 \pm 25$ \\
\hline
\end{tabular}

According to eqn (1), the linear regression of the experimental data $\Delta \mathrm{L} / \mathrm{F}$ vs. $1_{0} / \mathrm{A}$ (cf. Fig. 4) yields a straight line with a constant slope $1=\mathrm{E}$ (the inverse of Young modulus) and the intercept $\mathrm{C}_{\mathrm{S}}$ giving the system compliance. Fig. 7 shows the plot. The tensile modules for the fishing net polyfilament fibre was hereby found to $330 \mathrm{MPa}$ but with $\mathrm{R}^{2}=0.72$, this is not an exact number but more an order of magnitude. Spadea et al. [4] reported Youngs modulus of 724-728 MPa for their monofilament recycled fishing nets, which is also very low considering that Youngs modulus nylon 6 at the virgin state is in the range 1-3 GPa. 


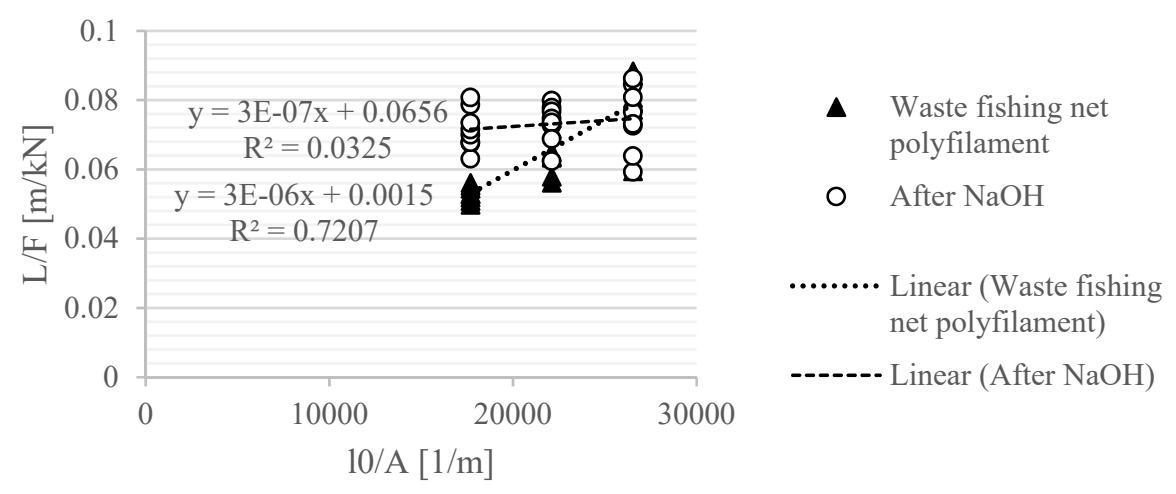

Figure 7: $\Delta \mathrm{L} / \mathrm{F}$ vs. 10/A plots to determine Young-modulus.

Similar tensile strength tests were made for the alkali treated samples, but here the number of fibres, which showed divided strength, was significantly higher than for the untreated fibres. In addition $\mathrm{R}^{2}$ was only 0.03 for the $\Delta \mathrm{L} / \mathrm{F}$ vs. $1_{0} / \mathrm{A}$ plots to determine E-modulus. A reason for the incoherent results and the poor $\mathrm{R}^{2}$ can probably be found in the loosened structure of the polyfilament after the submersion (Fig. 5(b)) compared to before (Fig. 3(a)) and thus the tension was not applied equally to the monofilaments.

The tensile strength of new nylon 6 is $540-1080 \mathrm{MPa}$ [12], and compared to this, the measured tensile strength $(260 \pm 25 \mathrm{MPa}$, Table 2$)$ of the waste fishing net fibers was only half of the lowest value. The used diameter $(\mathrm{d}=1.2 \mathrm{~mm})$ does not cover a cross section of the pure nylon as the measurements were made with polyfilaments. An optimal packing of monofilaments with circular cross section would be a hexagonal packing i.e. packing density 0.91. Calculating the tensile strength for the polyfilament based on $91 \%$ of the diameter is nylon result in a tensile strength of $285 \mathrm{MPa}$, which is still much lower than the range given for new nylon 6 . The packing density might very well be less than optimal, but it seems unlikely that the packing density was less than $50 \%$. Previous studies reported a tensile strengths of waste fishing net monofilament fibres of nylon 6 are: $330 \mathrm{MPa}$ [3] and $440 \mathrm{MPa}$ [4]. Thus it seems as the tensile strength of waste fishing nets is generally less than the range given for new nylon 6. On exposure to UV radiation over a long period of time, nylon 6 undergo photo-oxidative degradation manifested by loss of strength [12], and this may be one cause for the lost tensile strength. The waste fishing net of the present work was sampled at a dumpsite, and it is not known for how long, the net had been exposed to UV light prior to sampling, but it is very likely that it has lost some strength compared to new produced net.

The overall characteristics found for the nylon 6 waste fishing net polyfilaments are summarized in Table 2, where the similar parameters for the commercial Durus fibres are given for comparison (values from the data sheets provided by the PP Nordica).

\subsection{Mortar reinforced with fishing net fibres}

A homogeneous distribution of fibres could not be obtained for $2 \mathrm{wt} . \%$ of $4 \mathrm{~cm}$ fishing net fibres and Durus. Except from at these, the fishing net fibres distributed relatively evenly over the mortar specimens. Fig. 8 shows the transverse cross section after the bending test. 
Table 3: Characteristics of waste fishing net fibres and commercial fibres (data from data sheet from supplier).

\begin{tabular}{|l|c|c|}
\hline & Waste fishing net fibre & Durus \\
\hline Polymer & Nylon 6 polyfilament & PP monofilament \\
\hline Melting point $\left({ }^{\circ} \mathrm{C}\right)$ & 215 & 165 \\
\hline Ignition temperature $\left({ }^{\circ} \mathrm{C}\right)$ & $>350$ & $>360$ \\
\hline Diameter $(\mathrm{mm})$ & 1.2 & 0.9 \\
\hline Length $(\mathrm{mm})$ & $20 \pm 1.0$ & $45 \pm 2$ \\
\hline Tensile strength $(\mathrm{MPa})$ & $26 \pm 2.0$ & 465 \\
\hline Youngs modulus $(\mathrm{MPa})$ & $\sim 330$ & 3350 \\
\hline
\end{tabular}

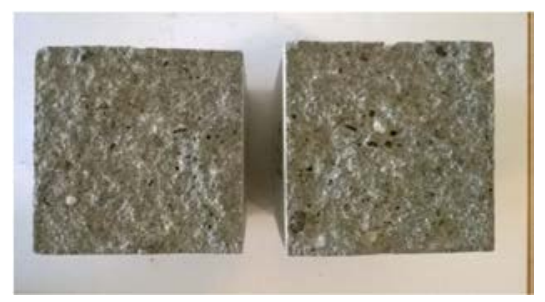

(a)

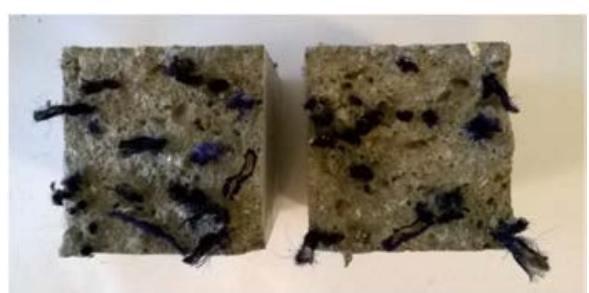

(b)

Figure 8: Transverse cross section of mortar bars. (a) Ref. and; (b) 2 wt.\% 2 cm long polyfilament waste fishing net fibres.

Load-deflection curves of mortar specimens reinforced with $2 \mathrm{~cm}$ long waste fishing net fibres after different curing time (7, 14 and 28 days), $4 \mathrm{~cm}$ long fibres after 28 days and Durus fibres after 28 days are shown in Fig. 9. As expected, the unreinforced mortar specimen exhibited brittle behaviour in bending due to a sudden rupture on reaching the peak load (Fig. 9(a)-(c)). The fibre-reinforced mortar specimens all showed considerable post-peak resources. After the peak load and sudden drop, the curves for the fishing net reinforced mortar specimens all exhibit either an almost constant load (at the lowest fibre contents 0.5 wt.\%) or a slightly increasing load until a deflection of about $2 \mathrm{~mm}$, where after the loads drops slowly again. The post-peak load varied between the triplicated measurements for each fibre percentage of the $2 \mathrm{~cm}$ long fishing net fibres (Fig. 9(a)-(c)). For the $4 \mathrm{~cm}$ long fishing net fibres, on the other hand, the variation was much smaller. The mortar bars reinforced with the Durus fibres exhibited a more stepwise post-peak behaviour than the fishing net reinforced mortars. One explanation may be that the Durus fibres are monofilaments and thus each fibre breaks at once on the contrary to the monofilament fishing net fibres.

The post-crack load for the $2 \mathrm{wt} . \%$ fishing net reinforced mortar was at the same level as the post crack load for $1 \mathrm{wt} . \%$ Durus fibres, which is a highly encouraging result.

After 7 days of curing, the load deflection curves after post-cracking were somewhat overlapping the different fibre contents (Fig. 9(a)), but after 14 days, the curves for the different fibre contents are separated and increasing with fibre content (Fig. 9(b) and (c)).

The flexural strength $\left(R_{f}\right)$ is calculated from the three point bending test as:

$$
R_{f}=\frac{1.5 \cdot F_{f} \cdot l}{b^{3}}
$$



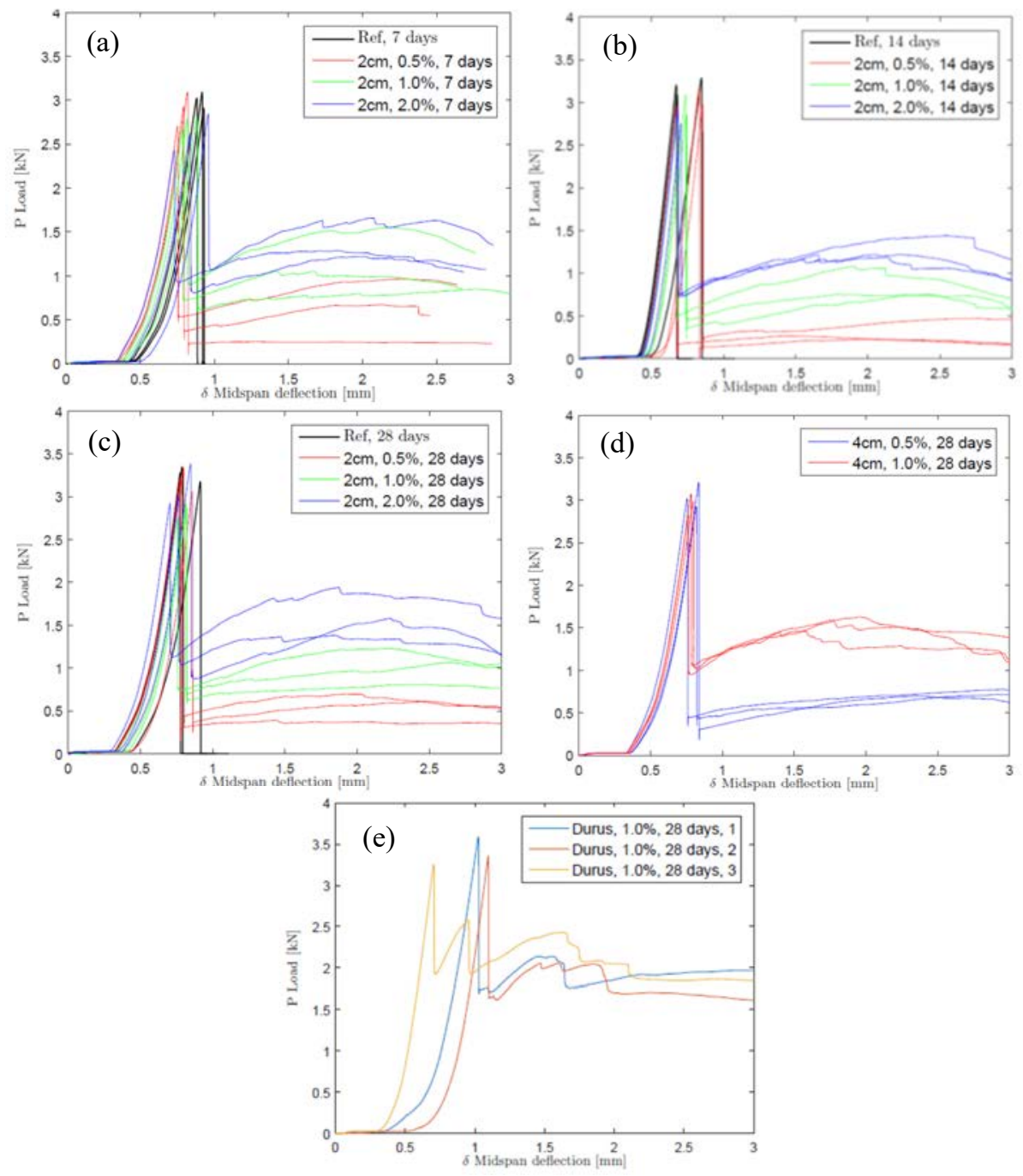

Figure 9: Load-deflection curves of mortar specimens reinforced with waste fishing net fibres. (a) $2 \mathrm{~cm}$ fibres, 7 days; (b) $2 \mathrm{~cm}$ fibres, 14 days; (c) $2 \mathrm{~cm}$ fibres, 28 days; (d) $4 \mathrm{~cm}$ fibres 28 days; and (e) Durus fibres 28 days.

where $F_{f}$ is the load at fracture, $l$ the distance between supports and $b$ the side of the square section of the specimens. The flexural strength is shown in Fig. 10. The flexural strength increases with increasing curing time as expected. An exception is however the flexural strength for reinforcement with $1 \mathrm{wt} . \%$ of the $2 \mathrm{~cm}$ long fishing net fibres. There is no obvious explanation for this exception, and it is considered as an irregularity, which can occur since each set of data is based on only 3 tests. On the contrary to the mortar specimens reinforced with fishing net fibres, the specimens reinforced with Durus had a slightly higher flexural strength than the reference. In the two published investigations with monofilament nylon 6 fishing net fibres [4], [5] the flexural strength was higher for the fibre reinforced mortar 
specimens than for the reference. In the two references, the 28 days flexural strength was lower (4.5 $\mathrm{MPa}$ and 4.8 $\mathrm{MPa}$ ) than in the present 7.7 MPa. The effect from the fibres must be expected stronger for a weaker mortar, and this can explain the decreased flexural strength in the present investigation. The flexural strength decreases with increasing fibre content (Fig. 10).

The 28 days compressive strength of the reference mortar was $46 \pm 4.6 \mathrm{MPa}$, and for all fibre reinforced mortar specimens, the compressive strength was lower (Fig. 11). The decrease of compressive strength if the fibre reinforced specimens is in accordance with literature [4], [5] and is explained by the deformable plastic fibres assume the role of voids in the cementitious matrix when compressive forces are applied.

The load-deflection curves are analysed as described in [12]. The flexural toughness is being calculated as the area under the load-deflection curve up to a target value of deflection:

$$
T_{\bar{\delta}}=\int_{0}^{\bar{\delta}} P \delta \mathrm{d} \delta .
$$

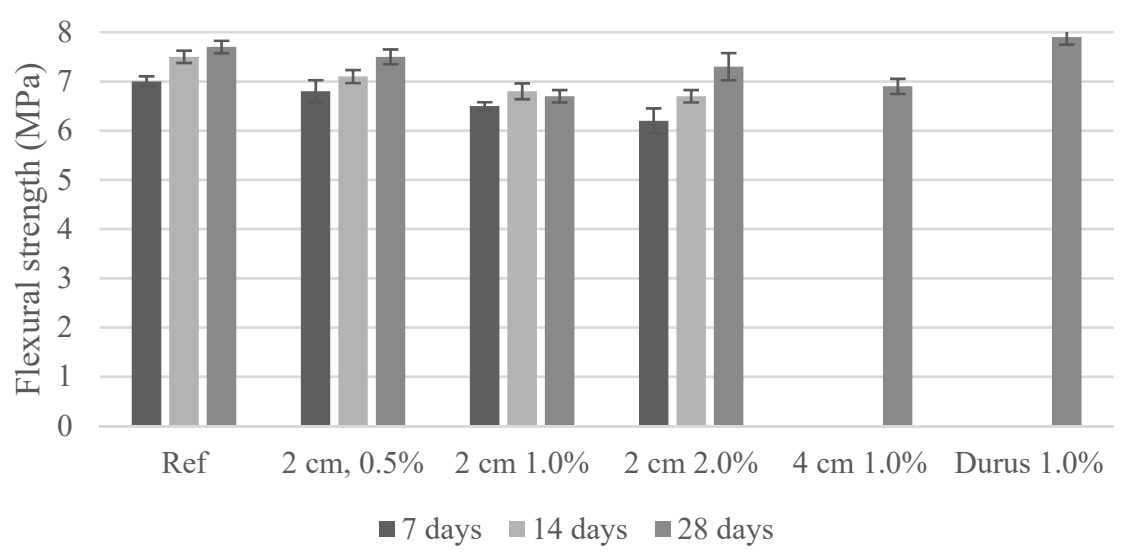

Figure 10: Flexural strength with standard deviation.

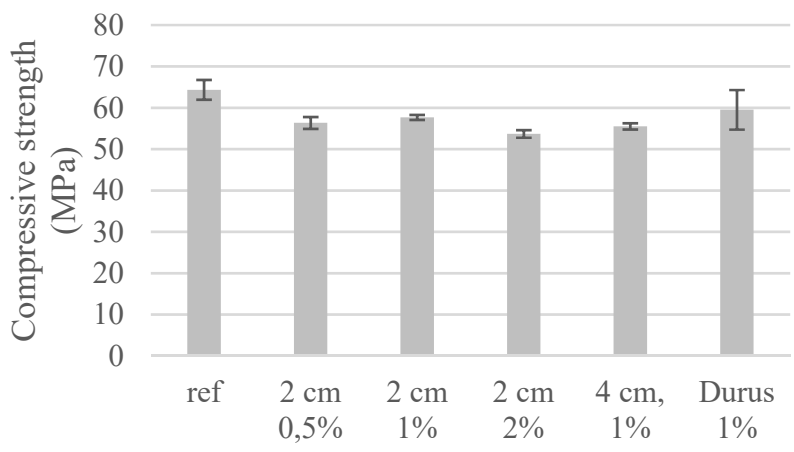

Figure 11: Compressive strength with standard deviation. 


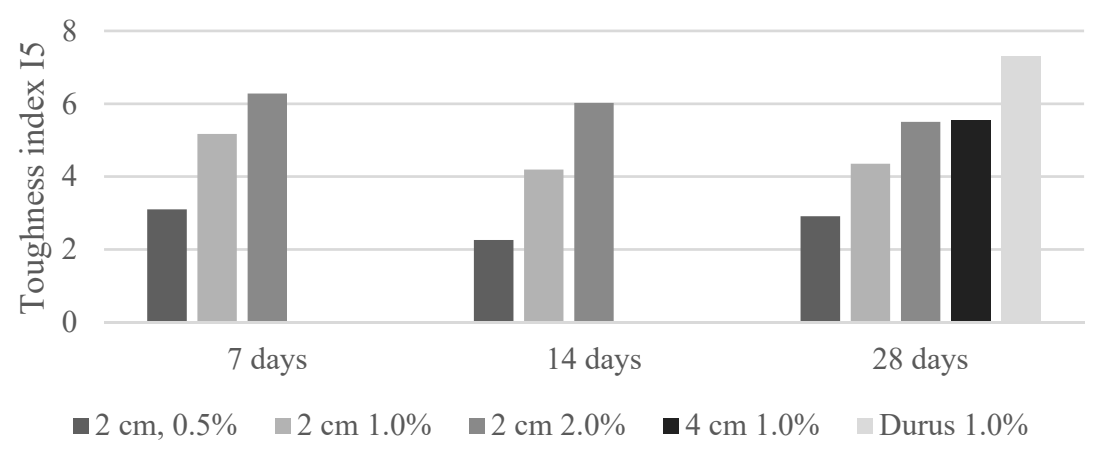

Figure 12: Toughness index (I5) for the fibre reinforced mortar specimens after different curing time.

The toughness for the critical deflection $\left(\mathrm{T}_{\delta \mathrm{cr}}\right)$ is the area under the curve until peak load. For calculation of the toughness indices, the areas under the curves until 2 and 3 times the critical deflection are also used, $\left(\mathrm{T}_{2 \delta \mathrm{cr}}\right.$ and $\mathrm{T}_{3 \delta \mathrm{cr}}$, respectively). The two toughness indices are:

$$
I_{2}=\frac{T_{2 \delta_{c r}}}{T_{\delta_{c r}}} \quad I_{5}=\frac{T_{3 \delta_{c r}}}{T_{\delta_{c r}}}
$$

This provides an easy comparison between the toughness values before and after initial crack. Fig. 12 shows the $I_{5}$. Toughness index $I_{2}$ showed exact the same pattern, but naturally with lower values. Compared to [4], [5] the $I_{5}$ for the mortar specimens with fishing net fibers of the present investigation is higher. After 28 days of curing, the $I_{5}$ was $2.4-3.4 \mathrm{MPa}$ (highest at $1.5 \mathrm{wt} . \%$ of $25 \mathrm{~cm}$ long monofilament fishing net fibers) in [4] and in [5] the range was 1.95-3.37 MPa (highest for $2 \mathrm{wt} . \%$ of $40 \mathrm{~mm}$ long monofilament fishing net fibers).

\section{CONCLUSIONS}

The investigated waste fishing net of nylon 6 have lost tensile strength and elasticity compared to new nylon 6. Still, polyfilament fibres cut from the waste fishing net showed encouraging results for reinforcement of concrete. The reinforced mortars could take significant post-crack loads, and at $2 \mathrm{wt} . \%$ this load was at the same level as with $1 \mathrm{wt} . \%$ of commercial fibres. The toughness index was at an interesting level as well.

\section{ACKNOWLEDGEMENT}

The study was part of the project "Circular Ocean" (http://www.circularocean.eu/), which is funded through the ERDF Interreg VB Northern Periphery and Arctic (NPA) Programme.

\section{REFERENCES}

[1] UNEP, Marine plastic debris and microplastics, 2016.

[2] Charter, M., Summary of the Findings of Port Related Feasibility Studies Related to the Collection and Recycling of Waste Fishing Nets and Ropes in Greenland, Ireland, Norway and Scotland. www.circularocean.eu/wp-content/uploads/2017/11/CircularOcean-Port-Reports-FINAL.pdf. 
[3] Bertelsen, I.M.G. \& Ottosen, L.M., Engineering properties of fibres from waste fishing nets. International Conference on Materials, Systems and Structures in Civil Engineering: Conference Workshop on Cold Region Engineering, Technical University of Denmark, Department of Civil Engineering. (BYG DTU Report, No. Byg R-352), pp. 7-16, 2016.

[4] Spadea, S., Farina, I., Carrafiello, A. \& Fraternali, F., Recycled nylon fibers as cement mortar reinforcement. Construction and Building Materials, 80, pp. 200-209, 2015. DOI: 10.1016/j.conbuildmat.2015.01.075.

[5] Orasutthikul, S., Unno, D. \& Yokota, H., Effectiveness of recycled nylon fiber from waste fishing net with respect to fiber reinforced mortar. Construction and Building Materials, 146, pp. 594-602, 2017. DOI: 10.1016/j.conbuildmat.2017.04.134.

[6] ASTM-C1557-14, Standard test method for tensile strength and young's modulus of fibers.

[7] Brandt, A.M., Fibre reinforced cement-based (frc) composites after over 40 years of development in building and civil engineering. Composite Structures, 86(1-3), pp. 39, 2008. DOI: 10.1016/j.compstruct.2008.03.006.

[8] Sim, J., Park, C. \& Moon, D., Characteristics of basalt fiber as a strengthening material for concrete structures. Composites Part B Engineering, 36(6-7), pp. 504-512, 2005. DOI: 10.1016/j.compositesb.2005.02.002.

[9] DS/EN-196-1, Methods of testing cement - part 1: Determination of strength.

[10] DS/EN-197-1, Cement - part 1: Composition, specifications and conformity criteria for common cements.

[11] Mukhopadhyay, S.K., Manufacturing, properties and tensile failure of nylon fibres. Handbook of Tensile Properties of Textile and Technical Fibres. A Volume in Woodhead Publishing Series in Textiles, pp. 197-222, 2009.

[12] ASTM-C1018, Standard test method for flexural toughness and first crack strength of reinforced concrete using beam with third-point loading. 